Surgery

\section{Thoracic empyema}

\section{A Jaffé, G Cohen}

\section{A role for primary video assisted thoracoscopic surgery?}

A long ago as 300 BC, Hippocrates commented that a person "with empyemata ... shall die on the fourteenth day, unless something favourable supervene". ${ }^{1}$ After identifying the affected side he would recommend drainage with a tin tube. However, in the ensuing years, great debate surrounded the benefits of opening the chest. When Napoleon's surgeon, Dupuytren, developed an empyema in 1835, he was heard to comment that "he would rather die at the hands of God than of surgeons". He lived 12 days. Over one and a half centuries later the role of the surgeon in the management of empyema remains controversial. This leading article will review the potential role for primary video assisted thoracoscopic surgery (VATS) in thoracic empyema in children.

\section{TREATMENT AIMS IN EMPYEMA}

The aim of empyema treatment is to return the lung to normal function. This is achieved by sterilising the pleural cavity with antibiotics, drainage of fluid, and expansion of the lung. There are three stages in empyema formation. ${ }^{2}$ The first is the exudative stage, during which fibrinous material forms on both pleural surfaces. As more fibrin is deposited, the pleural surfaces may be joined by fibrinous septae which cause the fluid to become loculated. This is the fibrinopurulent stage and may last several weeks. The final stage is the organisational stage, and is characterised by proliferation of fibroblasts on the pleural surfaces, which form an inelastic covering preventing adequate lung expansion (fibrothorax). Early intervention prevents this third stage from developing. Currently the primary treatment options are: antibiotics alone; recurrent thoracocentesis; insertion of chest drain alone or in combination with fibrinolytics; open decortication; or VATS.

\section{THE RATIONALE FOR VATS}

Since the 1960s there has been a growing interest in the use of minimally invasive surgery in children. Initial procedures were diagnostic, but with the development of more sophisticated instruments and imaging systems, more procedures are being performed endoscopically, including thoracoscopic surgery.

Figure 1 Surgical scars: VATS.
VATS is performed under general anaesthesia with either one or both lungs ventilated, depending on the size of the child. Two or three ports are made in the chest with the child in the lateral decubitus position (fig l). One port is utilised for the camera and the others for grasping instruments, which can be rotated round the ports if required. Insufflation of the chest cavity with $\mathrm{CO}_{2}$ aids collapse of the lung for better visualisation. In empyema, the free fluid is evacuated and loculations drained under thoracoscopic visualisation. The fibrinous adhesions are separated and the pleural debris removed from the pleural lining using endoscopic grasping forceps or by extensive irrigation and suction. Following the procedure, one or two chest drains are then placed in the portholes.

VATS has the advantage over open surgery of limiting the morbidity to skin, muscles, nerves and supporting structures which occurs following a large surgical incision (fig 2). These include: pain, both acute and long term; infection; limitation of movement; and cosmetic scarring. Scoliosis can occur in children following open thoracotomy with a reported incidence of up to $15 \%$. In addition to damaging the superficial structures, exposing the internal organs in small children may cause drying of tissues and impair healing. Furthermore, endoscopic surgery offers the advantage of better visualisation of internal structures compared to open surgery. In VATS, the scars are smaller (fig l), and the decreased exposure of underlying structures theoretically leads to quicker healing and reduced morbidity.

Kern and Rodgers first used VATS for the treatment of empyema in children in 1993. ${ }^{3}$ It was initially used as rescue treatment following failure of therapy with antibiotics and closed chest drain insertion. Since then there have been various case series reports of its successful use in children, which has led to an increasing debate regarding its potential in the treatment of empyema. ${ }^{3-12}$ The question, therefore, is whether VATS offers any advantage over other established therapies in the primary treatment of empyema in children?

\section{VATS VERSUS CHEST DRAIN ALONE}

In this issue, Satish et al describe the outcome in 14 children treated with chest drain only. ${ }^{13}$ Chest tube drainage occurred for eight days with a median hospital stay of 14 days (maximum stay 28 days). No patient needed a further surgical intervention. We have recently reviewed our experience with 21 children undergoing primary VATS compared to 54 treated with chest drainage alone. ${ }^{14}$ All patients had at least stage II empyema. We showed a significant reduction in days in hospital (7.4 versus 15.4 ) and chest tube drainage (4.0 versus

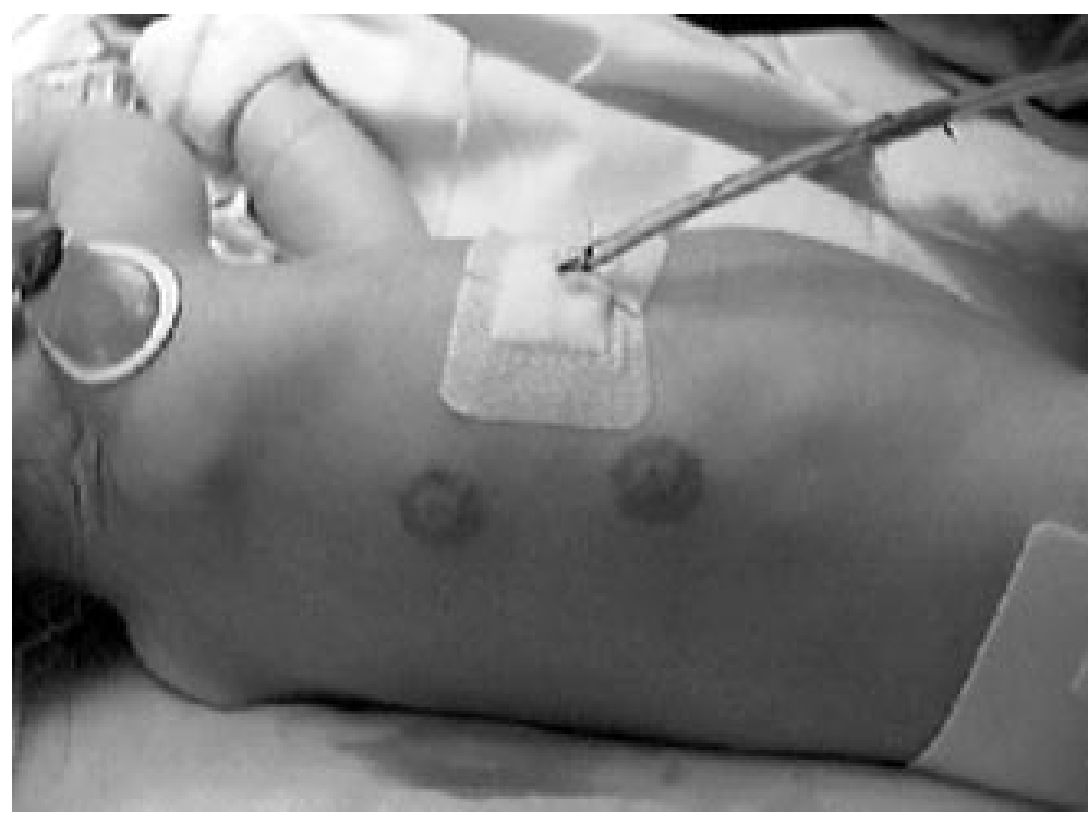




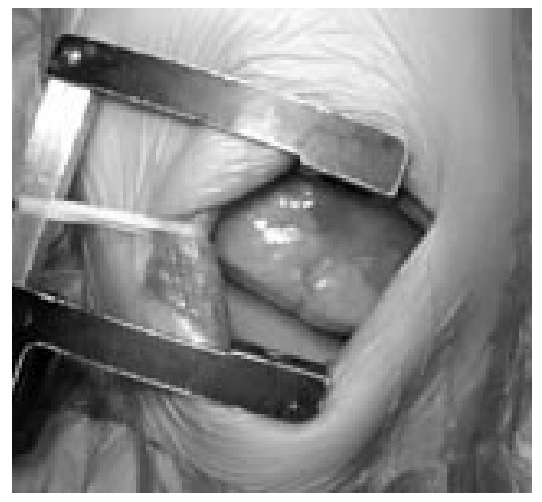

Figure 2 Surgical scars: open

decortication.

10.2) in the VATS group. Furthermore, $39 \%$ of patients treated with chest drain only required further surgical intervention. No child undergoing VATS had a subsequent open thoracotomy. The disparity in the number of children who required a further surgical intervention in these two studies probably reflects a difference in patient population. It is likely that in our series in a tertiary centre, patients had more advanced disease. We believe that VATS offers significant benefits over chest drain insertion alone because of the marked reduction in hospital stay and the need for further interventions.

\section{VATS VERSUS CHEST DRAIN AND FIBRINOLYTICS}

Previous uncontrolled studies have shown that urokinase is safe and has a role in the treatment of empyema. ${ }^{15-17}$ Thomson et al recently published the only prospective study assessing the role of fibrinolysis in childhood empyema in 58 children ${ }^{18}$ which has led to changes in medical management in many centres. They showed a significant reduction in length of stay in hospital compared to a saline control group (7.4 $v 9.5$ days), similar to that seen in our VATS series (7.4 days). ${ }^{14}$ However, it is likely that some patients did not have stage II disease, as approximately $50 \%$ had clear fluid and 22 had no loculations. Importantly, five (two in the treatment arm) required surgical decortication. This failure rate reflects that seen in our personal practice and has been reported as high as $20 \%$ in some series. ${ }^{19}$ In those patients who undergo VATS following failure of urokinase treatment, the procedure has to be converted to an open thoracotomy in approximately $15 \%$ of patients. ${ }^{20}$ Urokinase causes the intrapleural loculations to become very adhesive and increases the difficulty of the VATS procedure. Thus urokinase is likely to increase the chances of a child undergoing open decortication in those who fail medical treatment.

A recent Cochrane review concluded that VATS is superior to chest drain and fibrinolytics. ${ }^{22}$ However, only one study in adults met the inclusion criteria. ${ }^{23}$ The only study to compare urokinase and primary VATS in children was a retrospective, uncontrolled review of clinical practice between 1992 and 1998. ${ }^{4}$ The group who received VATS had a significant reduction in total length of hospital stay and number of procedures. To date, no adequate data exist in children comparing VATS with fibrinolytics. We are currently conducting a prospective study to answer this question.

\section{VATS VERSUS OPEN SURGERY}

Open surgical decortication is often carried out following the failure of medical management. ${ }^{24}$ However, some centres advocate primary open decortication as the treatment of choice. Carey et al audited 18 children who underwent primary open limited thoracotomy for stage II and III empyema. ${ }^{25}$ The median length of stay was four days, with all chest drains removed within 48 hours. In a recent study by Pierrepoint et al, patients with urokinase and pigtail insertion were discharged quicker following the procedure (5.6 days) than those undergoing a primary thoracotomy (6.9 days). ${ }^{26}$ To our knowledge, there is no study that directly compares primary VATS with open decortication in children. Subramanium et al showed a reduced stay in hospital in the VATS arm compared to open thoracotomy in those referred following the failure of medical management. ${ }^{9}$ Critics of open decortication cite significant morbidity such as a large surgical scar, wound infection, persistent air leaks, recurrence, and bleeding as a reason to avoid open surgery. ${ }^{27-30}$ The morbidity associated with a large thoracotomy scar cannot be ignored (fig 2 ), and therefore VATS may offer significant advantages over open thoracic surgery.

\section{LACK OF EVIDENCE BASED GUIDELINES}

From the above discussion it is clear that properly conducted studies assessing the treatment options in childhood empyema are lacking. ${ }^{31}$ Adult data cannot be extrapolated to children, as empyema in adulthood is a different disease. Most of the paediatric studies are retrospective and are hampered by studying different patient populations. Furthermore, the diagnosis and staging of empyema in these studies is not rigorous. The lack of diagnostic and prognostic markers in pleural fluid and detailed imaging makes studies difficult to compare. Empyema is not one disease. It is a disease which evolves, and thus, it is likely that medical management may be useful only in the early stages. Furthermore, there needs to be an improvement in measurements of outcome. While most studies are obsessed with time in hospital and lung structure on imaging, very few studies have undertaken lung function, which is the most important end point.

\section{CONCLUSIONS}

It is likely that with improved instrumentation and increased training, VATS will become increasingly familiar to the paediatric surgeon. It is also foreseeable that with the development of new medications, surgery may be superseded..$^{32}$ In the interim, however, there is a desperate need for properly controlled studies. Until this occurs, the treatment a child receives will continue to depend on local practice and bias, which is not necessarily the best for the child.

Arch Dis Child 2003;88:839-841

\section{Authors' affiliations}

A Jaffé, Consultant and Honorary Senior Lecturer in Respiratory Research, Portex Respiratory Medicine Unit, Great Ormond Street Hospital for Children NHS Trust and Institute of Child Health, Great Ormond Street, London WCIN 3JH, UK

G Cohen, Chief of Pediatric Cardiothoracic Surgery and Associate Professor of Surgery, Seattle Children's Hospital, University of Washington School of Medicine, USA

Correspondence to: Dr A Jaffé, Portex Respiratory Medicine Unit, Great Ormond Street Hospital for Children NHS Trust and Institute of Child Health, Great Ormond Street, London WCIN 3JH, UK; a.jaffe@ich.ucl.ac.uk

\section{REFERENCES}

1 Hippocrates. The book of Hippocrates. In: Adams F, ed. The genuine works of Hippocrates. London: C and J Adlard Printers, 1849

2 American Thoracic Society. Management of nontuberculous empyema. Am Rev Respir Dis 1962;85:935-6.

3 Kern JA, Rodgers BM. Thoracoscopy in the management of empyema in children. J Pediatr Surg 1993;28:1 128-32.

4 Doski JJ, Lou D, Hicks BA, et al. Management of parapneumonic collections in infants and children. J Pediatr Surg 2000;35:265-8.

5 Tonz M, Ris HB, Casaulta C, Kaiser G. Is there a place for thoracoscopic debridement in the treatment of empyema in children? Eur $J$ Pediatr Surg 2000;10:88-91.

6 Davidoff AM, Hebra A, Kerr J, et al. Thoracoscopic management of empyema in children. J Laparoendosc Surg 1996;6/suppl 1):S51-4.

7 Rodriguez JA, Hill CB, Loe WA, et al. Video-assisted thoracoscopic surgery for children with stage II empyema. Am Surg 2000;66:569-72.

8 Merry CM, Bufo AJ, Shah RS, et al. Early definitive intervention by thoracoscopy in pediatric empyema. J Pediatr Surg 1999;34:178-80.

9 Subramaniam R, Joseph VT, Tan GM, et al. Experience with video-assisted thoracoscopic surgery in the management of complicated pneumonia in children. J Pediatr Surg 2001;36:316-19.

10 Meier AH, Smith B, Raghavan A, et al. Rational treatment of empyema in children. Arch Surg 2000;135:907-12.

11 Kercher KW, Attorri RJ, Hoover JD, et al. Thoracoscopic decortication as first-line therapy for pediatric parapneumonic 
empyema. A case series. Chest 2000;118:24-7.

12 Patton RM, Abrams RS, Gauderer MW. Is thoracoscopically aided pleural debridement advantageous in children? Am Surg 1999:65:69-72.

13 Satish B, Bunker M, Seddon P. Management of thoracic empyema in childhood: does the pleural thickening matter? Arch Dis Child 2003:88:918-21.

14 Cohen G, Hiortdal V, Ricci M, et al. Primary thoracoscopic treatment of empyema in children. J Thorac Cardiovasc Surg 2003; 125:79-84.

15 Krishnan S, Amin N, Dozor AJ, et al. Urokinase in the management of complicated parapneumonic effusions in children. Chest 1997; 112:1579-83.

16 Kornecki A, Sivan Y. Treatment of loculated pleural effusion with intrapleural urokinase in children. J Pediatr Surg 1997;32: 1473-5.

17 Moulton JS, Benkert RE, Weisiger KH, et al. Treatment of complicated pleural fluid collections with image-guided drainage and intracavitary urokinase. Chest 1995; 108:1252-9.
18 Thomson $\mathbf{A H}$, Hull J, Kumar MR, et al. Randomised trial of intrapleural urokinase in the treatment of childhood empyema. Thorax 2002;57:343-7.

19 Kilic N, Celebi S, Gurpinar A, et al. Management of thoracic empyema in children. Pediatr Surg Int 2002;18:21-3.

20 Bouros D. Antoniou KM, Chalkiadakis G, et al. The role of video-assisted thoracoscopic surgery in the treatment of parapneumonic empyema after the failure of fibrinolytics. Surg Endosc 2002;16:151-4.

21 Sit SC, Cohen G, Jaffé A. Urokinase in childhood empyema. Thorax 2003;58:93.

22 Coote N. Surgical versus non-surgical management of pleural empyema. Cochrane Database Syst Rev 2002;2:CD001956.

23 Wait MA, Sharma S, Hohn J, et al. A randomized trial of empyema therapy. Chest 1997;111:1548-51.

24 Chan PW, Crawford O, Wallis C, et al. Treatment of pleural empyema. J Paediatr Child Health 2000;36:375-7.

25 Carey JA, Hamilton JR, Spencer DA, et al. Empyema thoracis: a role for open thoracotomy and decortication. Arch Dis Child 1998:79:510-13.

26 Pierrepoint MJ, Evans A, Morris SJ, et al. Pigtail catheter drain in the treatment of empyema thoracis. Arch Dis Child 2002:87:331-2.

27 Kosloske AM, Cartwright KC. The controversial role of decortication in the management of pediatric empyema. J Thorac Cardiovasc Surg 1988;96:166-70.

28 Golladay ES, Wagner CW. Management of empyema in children. Am J Surg 1989:158:618-21.

29 Foglia RP, Randolph J. Current indications for decortication in the treatment of empyema in children. J Pediatr Surg 1987;22:28-33.

30 Hull J, Thomson A. Empyema thoracis: a role for open thoracotomy and decortication [letter]. Arch Dis Child 1999:80:581.

31 Khakoo GA, Goldstraw P, Hansell DM, et al. Surgical treatment of parapneumonic empyema. Pediatr Pulmono 1996;22:348-56.

32 Idell S, Mazar A, Cines D, et al. Single-chain urokinase alone or complexed to its receptor in tetracycline-induced pleuritis in rabbits. Am J Respir Crit Care Med 2002;166:920-6.

\section{STAMPS IN PAEDIATRICS}

\section{Smallpox vaccination}

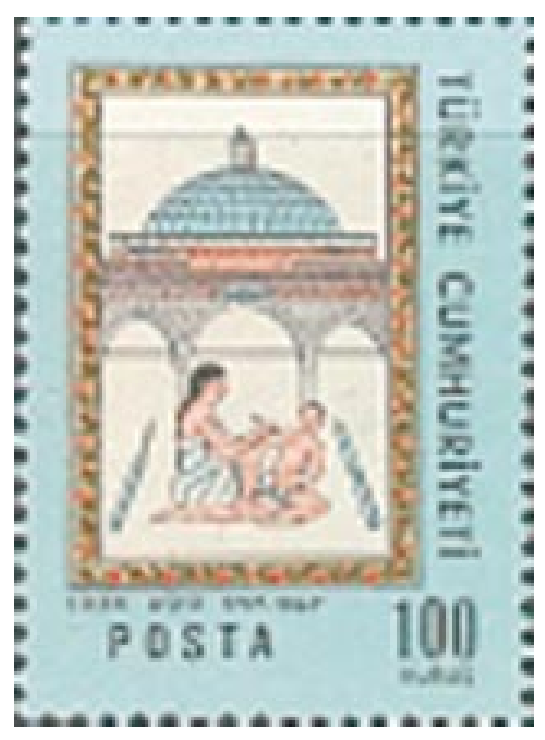

t is known that Lady Mary Wortley Montagu occupies an important place in the medical history for her efforts in smallpox vaccination. While in Turkey with her British ambassador husband, she vaccinated her 5 year old son. After returning to her own country she performed the same thing on her daughter (in 1721) and subsequently caused the widespread increase of vaccination in England.

She contributed just one identified text to the war against smallpox, writing not under her own name, but as "a Turkey merchant" — a pseudonym that misrepresents her class as well as her gender, but makes no claim to medical qualification. No wonder: her essay, published in the Flying Post at the height of the controversy, is an outright attack on the medical profession.

The procedure was quite safe in the hands of Turkish women. According to her notes, the old woman in Turkey made a tiny scratch with a needle and inserted a tiny quantity of smallpox virus just under the skin.

Interestingly, the Royal Society heard a paper on Turkish inoculaton in 1714. As a result, although Jenner was shown to be the inventor of the vaccine, the efforts of Lady Mary Wortley Montagu, deserving more appreciation than Jenner, should not be forgotten.

The stamp, from Turkey in 1967, depicts the 250th anniversary of the first smallpox vaccination.

S Kula 